\title{
Gas Chromatography-Mass Spectrometric Characteristics and Assay of tele-Methylhistamine ${ }^{1}$
}

\author{
Lindsay B. Hough, ${ }^{2}$ Philip L. Stetson, and Edward F. Domino \\ Department of Pharmacology, University of Michigan, Ann Arbor, Michigan 48109
}

Received May 25, 1978

\begin{abstract}
To date, tele-methylhistamine, the product of enzymatic histamine methylation, has not been measured by a suitable method. Tele- and pros-methylhistamine both react quantitatively with trifluoroacetic and heptafiuorobutyric anhydrides at room temperature under anhydrous conditions to yield either mono- or bis-derivatives in the absence or presence of pyridine, respectively. The extraction of tissue homogenates, derivatization, and analysis by gas chromatography-mass fragmentography permits the detection of $1 \mathrm{ng} / \mathrm{ml}$ tele-methylhistamine, using pros-methylhistamine as the internal standard. Rat brain contains telemethylhistamine in a concentration similar to that of histamine $(42 \mathrm{ng} / \mathrm{g})$. The content of this amine in tissue has been compared with that obtained by other methods.
\end{abstract}

The biotransformation of histamine is brought about by two distinct enzymes, diamine oxidase (EC 1.4.3.6), and histamine methyltransferase (EC 2.1.1.8) (1). The latter enzyme methylates histamine, producing tele-methylhistamine (1-methyl-4- $(\beta-$ aminoethyl)-imidazole) (2). Figure 1 shows the structure of tele-methylhistamine $(t-$ $\mathrm{MH}){ }^{3}$ which has also been called 1,4 -methylhistamine, 1-methylhistamine, and 3-methylhistamine [see (3) for nomenclatural discussion]. In addition to the substantial formation of this substance in nonneuronal tissue, its synthesis in brain is probably quantitative from histamine, since histamine oxidation does not occur in mammalian brain (4). Brain histamine methylation has, in fact, been suggested as a neuronal inactivation mechanism (5). We have recently shown $t$-MH to be a substrate for mono-

\footnotetext{
1 Supported in part by the Psychopharmacology Research Fund (Domino).

Present address: Department of Pharmacology, $\mathrm{Mt}$. Sinai Medical School, One Gustave Levy Place, New York, N. Y. 10029.

${ }^{3}$ Abbreviations used: $t-\mathbf{M H}$, tele-methylhistamine; p-MH, pros-methylhistamine; DMCS, $1 \%$ dimethyldichlorosilane; gcms, gas chromatography-mass spectrometry.
}

amine oxidase B (6) and it has also been shown to be as potent as histamine in depressing cortical neurons when applied iontophoretically (7).

In light of these considerations, it is not surprising that the measurement of $t-\mathrm{MH}$ in biological samples has been attempted. Fram and Green first identified $t-\mathrm{MH}$ in the brains of several species (8) and in human urine (9). Several tissues have been assayed for $t$-MH by solvent extraction, derivatization with dinitrofluorobenzene, separation by thin-layer chromatography, followed by elution and spectrophotofluorimetry $(10,11)$. These methods suffer greatly from lack of ease, efficiency, and sensitivity (i.e., $\mu \mathrm{g}$ detection limits).

This report describes several conditions for derivatizing $t$-MH. A method is also described for the isolation, derivatization, and detection of $t$-MH from several biological sources with a sensitivity of $1 \mathrm{ng} / \mathrm{ml}$. Our methods are compared with those of previous reports.

\section{METHODS}

Standard $t$-MH and pros-methylhistamine ( $p$-MH, Fig. 1) hydrochlorides were kindly 


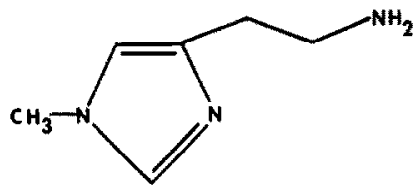

6.) - MEtron

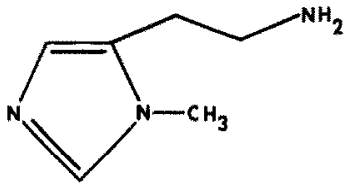

mos-methyomstantak

Fig. 1. The structures of tele- and pros-methylhistamines. This unambiguous nomenclatural system has been advocated by Black and Ganellin (3).

donated by Smith, Kline and French Ltd. (Hertfordshire, England) and stored in $0.01 \mathrm{~N} \mathrm{HCl}$ as stock solutions. $t$ - $\mathrm{MH}$ is also available from Calbiochem (La Jolla, Calif.) and designated by them as 1-MH. All content measurements refer to free base. Pyridine was distilled and stored over $\mathrm{KOH}$. Heptane was washed with $0.1 \mathrm{~N} \mathrm{HCl}, 0.1 \mathrm{~N}$ $\mathrm{NaOH}$, and distilled water twice. Sodium hydroxide $(10 \mathrm{~N})$ was stored in glass since semisolid residues were obtained in the assay after its prolonged storage in plastic. All other solvents were reagent grade and used from the bottle. Derivatizations were carried out in $1.0 \mathrm{ml}$ Reacti-Vials (Pierce, Rockford, Ill.). Glassware was silanized with $1 \%$ dimethyldichlorosilane (DMCS) in toluene (Pierce), All micropipetting was done with Eppendorf automatic micropipettes. Combined gas chroma- tography-mass spectrometry (gcms) was carried out using a Finnigan Model 3200 gcms programmed for total or selective ion monitoring. Gas chromatography separations were effected using 5 - $\mathrm{ft} \times 2-\mathrm{mm}$ silanized glass columns containing $1.7 \%$ OV-17 (Applied Sci., State College, Pa.) on Chromasorb G (80-100 mesh, acid washed, DMCS treated) at $160^{\circ} \mathrm{C}$ isothermal, with helium $(20 \mathrm{ml} / \mathrm{min})$ as the carrier gas. Mass spectra were obtained using an electron energy of $70 \mathrm{eV}$, and emission current of $1 \mathrm{~mA}$.

Anhydride derivatives of $t$ - and $p-\mathrm{MH}$ were prepared as described in Table 1. For the assay of $t$-MH (Fig. 2), fresh tissue was homogenized (10-20\% w/v) in ice-cold $0.4 \mathrm{~N} \mathrm{HClO}_{4}$ containing $20 \mathrm{ng} p$-MH as internal standard. Aliquots $(1.5 \mathrm{ml})$ were transferred to polypropylene conical micro-

TABLE 1

EI Mass Spectral Characteristics of Aliphatic Anhyoride Derivatives OF tele- AND pros-METHYLHISTAMINES ${ }^{a}$

\begin{tabular}{|c|c|c|c|c|c|c|c|c|c|}
\hline \multirow[b]{2}{*}{ Amine } & \multirow[b]{2}{*}{ Pyridine } & \multirow[b]{2}{*}{ Anhydride } & \multicolumn{6}{|c|}{$m / e$ ( $\%$ relative abundance) } & \multirow[b]{2}{*}{ dentity } \\
\hline & & & $\mathbf{M}^{+}$ & {$\left[\mathrm{M}-\mathrm{RCONH}_{2}\right]^{+}$} & {$\left[\mathrm{M}-\mathrm{RCONHCH}_{2}\right]^{+}$} & $\mathrm{C}_{7} \mathrm{H}_{7} \mathrm{~N}_{2} \mathrm{O}^{+}$ & $\mathrm{C}_{3} \mathrm{H}_{8} \mathrm{~N}_{2}^{+}$ & $\mathrm{CH}_{3} \mathrm{~N}=\mathrm{CH}^{+}$ & \\
\hline t-MH & + & Triffuoroacetic & $317(8)$ & $204(83), \mathrm{R}=\mathrm{CF}_{3}$ & $191(53), \quad R=C F_{3}$ & $135(100)$ & $94(17)$ & $42(81)$ & bis- \\
\hline p-MH & + & Trifluoroacetic & $317(3)$ & $204(61), R=C F_{3}$ & $191(\$ 1), \quad \mathbf{R}=\mathrm{CF}_{3}$ & $135(100)$ & $94(64)$ & $42(19)$ & bisw \\
\hline$t-\mathrm{MH}$ & + & Heptafluorobutyric & $517(11)$ & $304(80), R=C_{5} F_{7}$ & $291(42), \quad R=C_{3} F_{7}$ & $135(100)$ & $94(7)$ & $42(85)$ & bis- \\
\hline p-MH & + & Heptafluorobutyric & $517(2)$ & $304(62), R=C_{3} F_{7}$ & $291(34), \quad R=C_{3} F_{7}$ & $135(100)$ & $94(3)$ & $42(12)$ & bis- \\
\hline$i-\mathbf{M H}$ & - & Trifluoroacetic & $221(8)$ & $108(50), \mathbf{R}=\mathrm{CF}_{3}$ & $95(50), \quad R=C_{3}$ & - & $94(5)$ & $42(100)$ & mono- \\
\hline$p-\mathbf{M H}$ & - & Trifuoroacetic & $221(7)$ & $108(52), R=C F_{3}$ & $95(100), R=C F_{3}$ & - & $94(16)$ & $42(87)$ & mono* \\
\hline$t-\mathrm{MH}$ & - & Heptafuorobutyric & $321(7)$ & $108(97), \mathbf{R}=C_{3} F_{7}$ & $95(85), \quad R=C_{3} F_{7}$ & - & $94(4)$ & $42(100)$ & mono- \\
\hline$p$-MH & - & Heptafiuorobutyric & $321(4)$ & $108(80), R=C_{3} F$ & $95(100), R=C_{3} F_{7}$ & - & $94(11)$ & $42(63)$ & mono- \\
\hline$t-\mathbf{M H}$ & + & Acetic & $167(14)$ & $108(72), \mathrm{R}=\mathrm{CH}_{3}$ & $95(100), \mathrm{R}=\mathrm{CH}_{3}$ & - & $94(9)$ & $42(81)$ & mono- \\
\hline
\end{tabular}

${ }^{a}$ One microgram of amine was evaporated to dryness under a nitrogen stream. To the residue was added $15 \mu l$ of one of the above anhydrides with or without 5 w pyridine. Each vial was capped. mixed, and allowed to react for $10 \mathrm{~min}$ at room temperature followed by the addition of $0.1 \mathrm{~m}$. water, $0.2 \mathrm{ml} 5 \% \mathrm{NH}_{4} \mathrm{OH}$, and $0.7 \mathrm{ml}$ ethyl acetate. Following a 1 -min extraction, the layers were separated by centrifugation. The aqueous phase was removed and the organic layer was dried with $\mathrm{Na}_{4} \mathrm{SO}_{4}$, concentrated by evaporation, and assayed by gas chromatography-mass spectrometry as described. The mass/charge ratio (m/e) of the major fragments for each derivative are shown, along with the relative intensity of each fragment in parentheses. Each amine gave only one derivative under these conditions, identified at far right. 


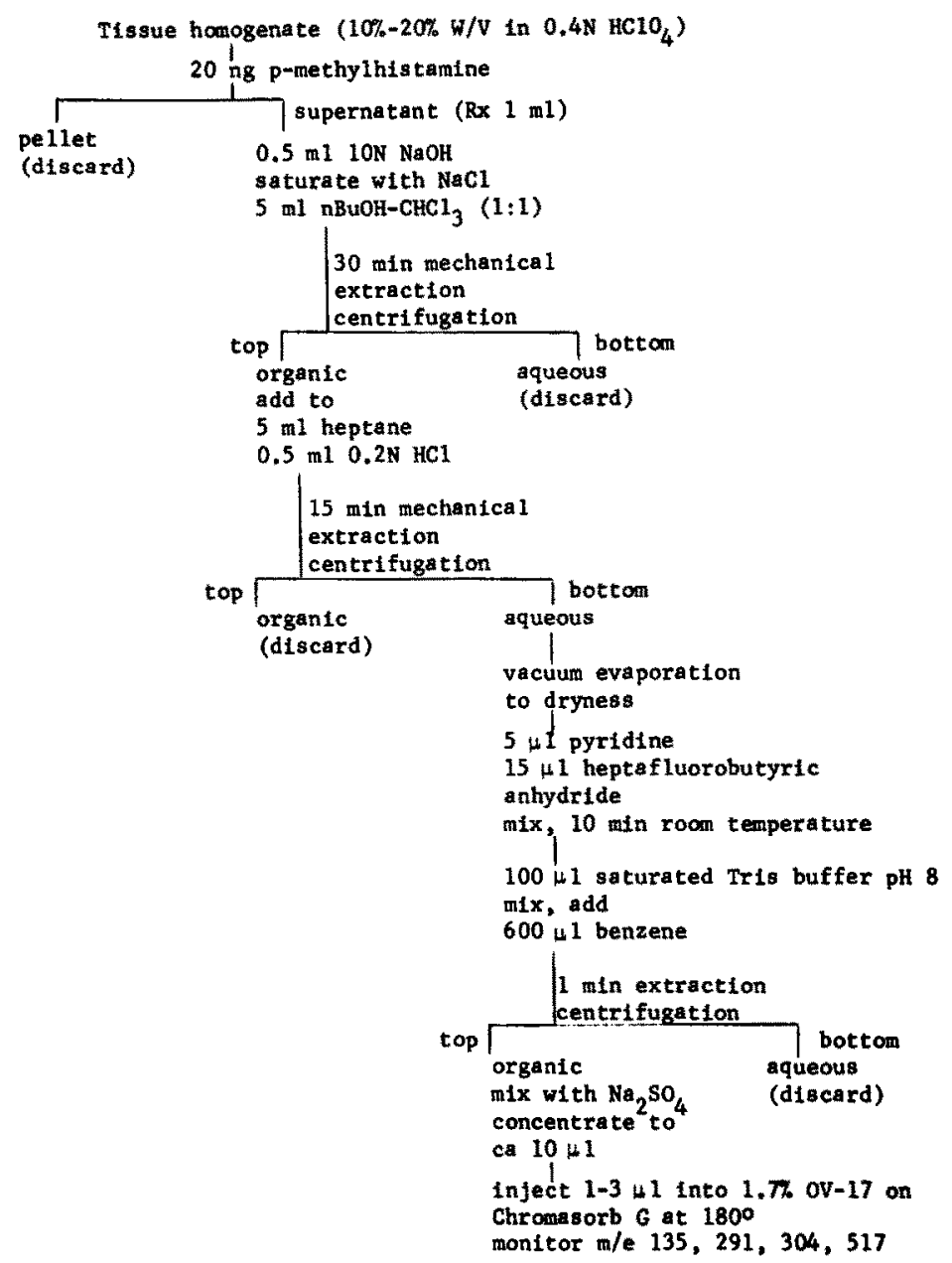

FIG. 2. Extraction, derivatization, and measurement of tele-methylhistamine. See Methods for details.

centrifuge tubes (KEW Sci., Columbus, Ohio) and centrifuged $5 \mathrm{~min}$ at $12,000 \mathrm{~g}$ in a Beckman table top centrifuge. One-milliliter aliquots of supernatant (or $\mathrm{HClO}_{4}$, containing standards) were placed in conical $15-\mathrm{ml}$ polypropylene centrifuge tubes, (KEW) made alkaline with $0.5 \mathrm{ml} 10 \mathrm{~N}$ $\mathrm{NaOH}$ and saturated with solid $\mathrm{NaCl}$. Following a 30 -s mixing by vortex, each tube received $5 \mathrm{ml}$ of $n$-butanol-chloroform (1:1). The tubes were capped and extracted mechanically for $30 \mathrm{~min}$. The layers were separated by subsequent centrifugation $(5 \mathrm{ml} \times 1000 \mathrm{~g})$ and each upper organic layer was transferred to a second centrifuge tube containing $0.5 \mathrm{ml} 0.2 \mathrm{~N} \mathrm{HCl}$ and $5 \mathrm{ml}$ heptane. A 15-min mechanical extraction and another centrifugation was followed by the careful removal of the upper organic layer by aspiration. The resulting aqueous fractions were transferred to Reacti-Vials and evaporated to dryness at room temperature with a vacuum centrifuge. Complete dryness was achieved within $1.5 \mathrm{~h}$, with a small residue remaining in the bottom of each vial. The residues received $5 \mu l$ pyridine, mixing, $15 \mu$ heptafluorobutyric anhydride, and another mixing. The $10-\mathrm{min}$ room temperature incubation was terminated by the addition of $100 \mu$ l saturated Tris buffer, pH 8. After the reaction subsided, each vial was mixed by vortex, insuring that all solids were dissolved. Benzene $(600 \mu \mathrm{l})$ was added and each vial was 
capped and thoroughly mixed for at least $1 \mathrm{~min}$. The layers were separated by centrifugation $(1000 \mathrm{~g} \times 5 \mathrm{~min})$ and the lower aqueous phases were removed with a syringe. The vials were recapped, mixed, and recentrifuged $(3000 \mathrm{~g} \times 10 \mathrm{~min})$, producing another small aqueous phase which was removed as before. Each vial then received a small amount of granular anhydrous $\mathrm{Na}_{2} \mathrm{SO}_{4}$ and its contents evaporated to $10 \mu \mathrm{l}$ with a stream of nitrogen. One $3 \mu \mathrm{l}$ of this solution was injected into the gcms system while specifically monitoring $m / e 304$ and 291.

To obtain the tissue data, female cats ( $2 \mathrm{~kg}$ ) were anesthetized with sodium pentobarbital (35 mg/kg, ip). For other purposes, these animals also received 300 units $/ \mathrm{kg}$ (iv) sodium heparin. Following the loss of reflexes, the tissues were dissected, weighed, and homogenized. Rat brains were assayed after decapitation.

\section{RESULTS}

Both $t$-MH and $p$-MH react with perfluoroacyl anhydrides in the presence of pyridine at room temperature to quantitatively yield the corresponding bis-perfluoroacyl derivatives within $10 \mathrm{~min}$. Radiochromatography of the isotopically labeled starting material $(t-\mathrm{MH})$ and product confirmed the quantitative nature of the reaction. Table 1 summarizes the EI mass spectra of $t-\mathrm{MH}$ and $p-\mathrm{MH}$ derivatives of trifluoroacetic (TFA), hepafiuorobutyric (HFBA), and acetic anhydrides formed in the presence or absence of pyridine at room temperature. The $t-\mathrm{MH}$ and $p-\mathrm{MH}$ derivatives exhibit similar spectra for each method of derivatization. The fragmentation patterns allow the identification of the derivatives as either bisor mono- as well as assign the location of the acyl groups. Thus, all of the monoderivatives are linked through the primary amine of the side chain since their spectra exhibit the appropriate molecular ions, as well as those ions corresponding to the loss of the uncharged amide (i.e., [M$\left.\mathrm{RCONH}_{2}\right]^{+}$). The bis-derivative spectra reveal the loss of the monoamide as well as the retention of a second fluoroacyl group on the imidazole ring. Although the substituent must either be in the 2- or 4-position, the spectra do not permit the distinction between these. Further evidence for the presence of derivatized primary amines in all cases is the loss of ninhydrin sensitivity. Table 1 indicates that the formation of the bis-derivatives of both methylhistamines requires the presence of pyridine as well as a halogenated anhydride at room temperature. Thus, the omission of pyridine uniformly yielded the monoderivatives as did the use of pyridine with acetic anhydride. In most cases, attempted derivatization at higher temperatures gave more than one product. Using the gc conditions described, all of the derivatives of Table 1 gave symmetrical total ion chromatograms with retention times between 1.5 and $6.8 \mathrm{~min}$ at $160^{\circ} \mathrm{C}$. In all cases, the $t$-MH derivative had the shorter retention time. The retention times of the bis-p-MH derivatives are nearly twice those of its $t$-isomer, allowing excellent separation.

The assay for $t$-MH is outlined in Fig. 2. $p$-MH serves as an ideal internal standard since it is extracted and derivatized similarly to $t-\mathrm{MH}$, yet the derivatives are easily separable by gc. The recovery of $t-\mathrm{MH}$ ranges from $75-90 \%$ through the procedure. As shown in Table 1, the HFBA derivatives of $t$ - and $p$ - $\mathrm{MH}$ give large $m / e$ 135,291 , and 304 in their mass spectra. Thus, the results of $t$-MH assays, as depicted in Fig. 2, are obtained by monitoring these ions following sample injection. Figure 3 shows the monitoring of $m / e 304$ and 291 following the assay of standards or brain extracts. Figure $3 \mathrm{~A}$ demonstrates the separation of the $t-\mathrm{MH}$ and $p-\mathrm{MH}$ derivatives of standards at $180^{\circ}$, with retention times of 1.15 and $2.18 \mathrm{~min}$, respectively. Figure $3 \mathrm{~B}$ indicates that brain tissue contains $t-\mathrm{MH}$, since its analysis produced 


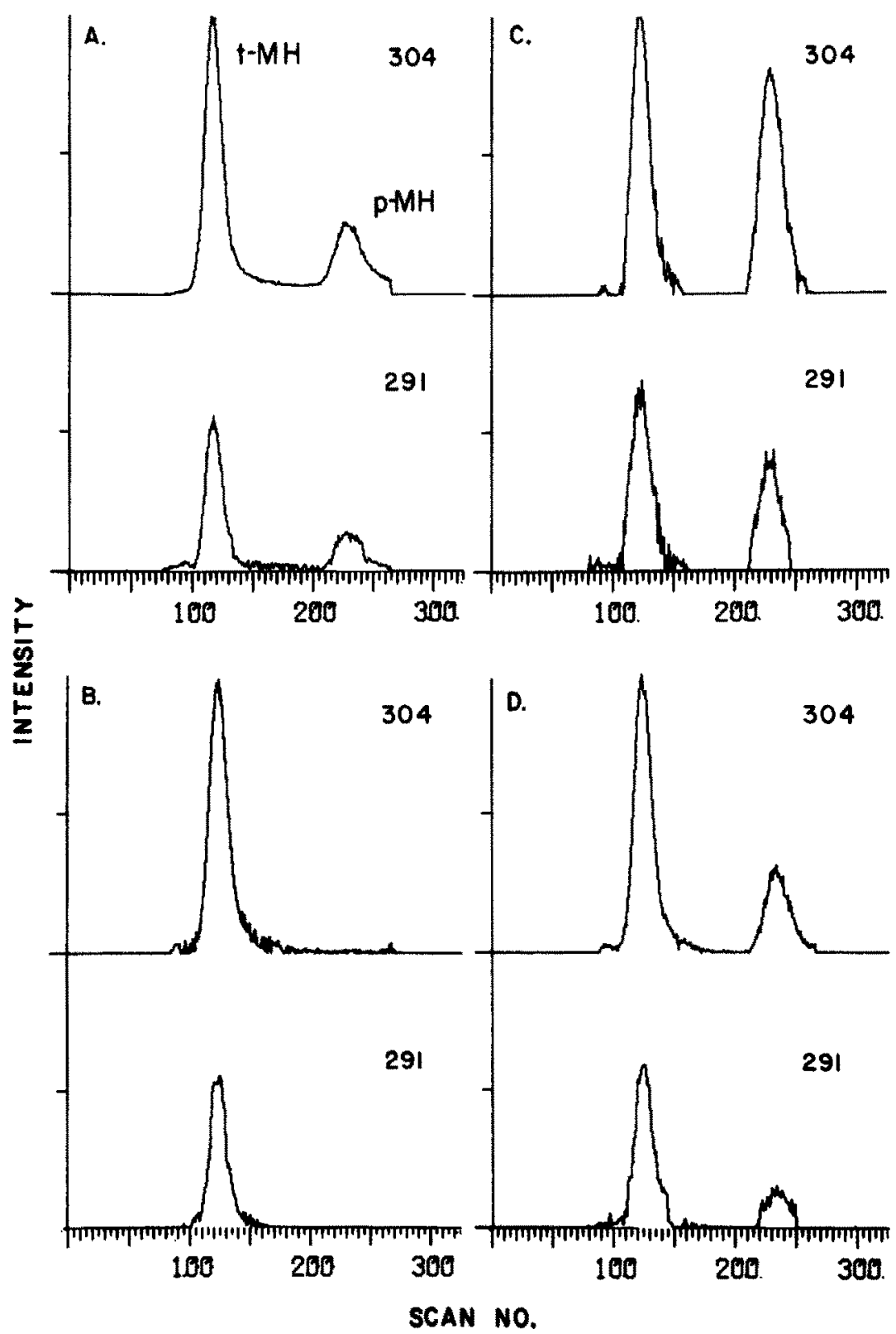

FIG. 3. Mass fragmentography of standard and rat brain tele-methylhistamine. Standards or supernatant fractions of brain homogenates were extracted, evaporated to dryness, derivatized, and analyzed by combined gas chromatography-mass spectrometry, as shown in Fig. 2 and described in detail under Methods. The gas chromatography was carried out with $1.7 \%$ OV-17 on Chromasorb $\mathrm{G}$ at $180^{\circ} \mathrm{C}$ using helium as the carrier gas. The ion intensities are plotted versus the time following sample injection, in scan numbers. Retention times for these bis(heptafluorobutyryl) derivatives are 1.15 and $2.18 \mathrm{~min}$ for tele $(t-)$ and pros ( $p-$ ) methylhistamine $(\mathrm{MH})$, respectively. Specific ion monitoring of m/e 304 and 291 are shown for the assay of (A) $20 \mathrm{ng} t-\mathrm{MH}$ and $p-\mathrm{MH}$ standards, (b) rat brain homogenate alone, (C) the same homogenate to which was added standard $p-\mathrm{MH}$, and (D) that homogenate containing both standards. The presence of $t$-MH in rat brain, as well as the absence of $p-\mathrm{MH}$ is evident. 
peaks in the scans of $m / e 304$ and 291 at the retention time of the standard and in the correct proportion. Furthermore, $p$ - $\mathrm{MH}$ is not detected in brain. The detection of internal standard after its addition to a brain homogenate is shown in Fig. 3C. Figure 3D further verifies the existence of endogenous $t$ - $\mathrm{MH}$, since the addition of standard $t-\mathrm{MH}$ to the homogenate increased the $t-\mathrm{MH} /$ $p$-MH ratio. Since $m / e 304$ is monitored for both compounds, the area corresponding to $t$ - $\mathrm{MH}$ divided by that of $p-\mathrm{MH}$ is proportional to the $t-\mathrm{MH}$ content when a constant amount of $p-\mathrm{MH}$ is added to each sample (Fig. 4). The $t$-MH standard curve is linear from 1 to $40 \mathrm{ng}$ as assayed from 1 $\mathrm{ml}$ of perchloric acid.

The $t$-MH content of several tissues has been obtained using the current method (Table 2). The results confirm the suggestion that many tissues contain $t-\mathrm{MH}$, although the content varies a great deal. Gastric mucosal $t$-MH was found to be 713 $\mathrm{ng} / \mathrm{g}$, two- or threefold higher than the content of lung and spleen which, in turn, is more than fivefold that found in liver and kidney. Rat brain $t$-MH is $42.4 \mathrm{ng} / \mathrm{g}$, similar to that found earlier in guinea pig brain. Furthermore, none of the tissues contained measurable $p$-MH when assayed without the addition of this internal standard.

\section{DISCUSSION}

Under the conditions described, the derivatization of $t$ - and $p-\mathrm{MH}$ with perhaloaliphatic anhydrides quantitatively produces one compound which has been identified in all cases by mass spectrometry. Furthermore, the heptafluorobutyryl derivatives are known to be stable in dry benzene up to $3 \mathrm{~h}$ at room temperature. Their stability has not been systematically studied beyond this point. Navert (12) reported the gc characteristics of HFBA and TFA derivatives of $t$ - and $p-\mathrm{MH}$. Our results confirm

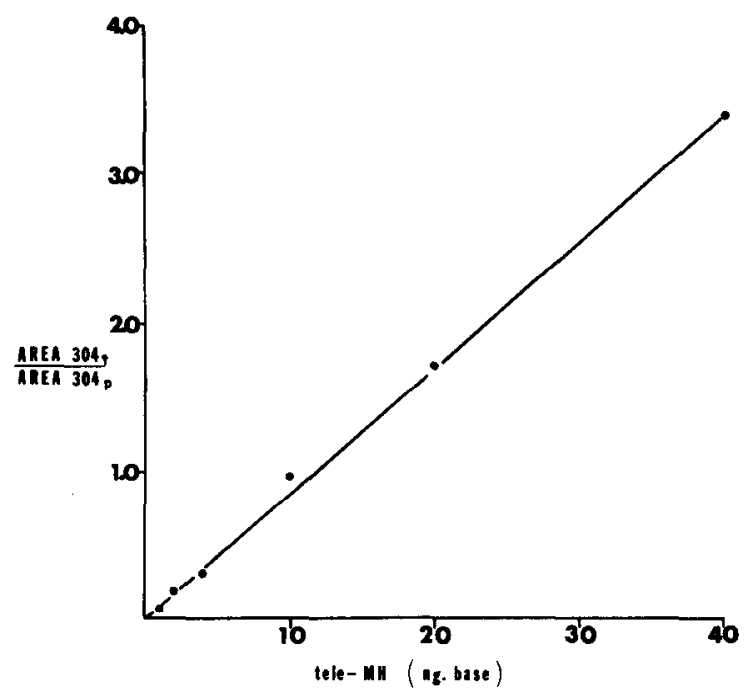

FIG. 4. Standard curve for tele-methylhistamine. One-milliliter samples containing 1-40 telemethylhistamine $(t-\mathrm{MH})$ and $20 \mathrm{ng}$ pros-methylhistamine ( $p-\mathrm{MH})$ were extracted, evaporated to dryness, and derivatized with heptafluorobutyric anhydride as described in Fig. 2 and under Methods. These derivatives were assayed using combined gas chromatography-mass spectrometry. Monitoring $m / e 304$ (the major fragment of both derivatives) yields two peaks, whose areas are plotted as shown. The area under $m / e \quad 304$ corresponding to $t-\mathrm{MH}$ is linear with $t-\mathrm{MH}$ concentration, when corrected for recovery by dividing by the m/e 304 area corresponding to p-MH. Each point was determined from one sample injection of standards assayed in single tubes. 
TABLE 2

tele-Methylhistamine Content of Some Tissues ${ }^{a}$

\begin{tabular}{llccc}
\hline \multicolumn{1}{c}{ Tissue } & Species & $\begin{array}{c}t \text {-MH } \\
(\mathrm{ng} / \mathrm{g})\end{array}$ & $\begin{array}{c}\text { Literature } \\
(\mathrm{ng} / \mathrm{g})\end{array}$ & Reference \\
\hline Whole brain & Rat & 42.4 & Not detected & 18 \\
& Guinea pig & - & 72 & 10 \\
Cerebellum & Cat & 94.9 & 100 (cortex) & 18 \\
Cerebral cortex & Cat & 174.6 & 300 & 18 \\
Gastric mucosa & Cat & 712.6 & 1100 & 18 \\
Lung & Cat & 183.1 & 700 & 18 \\
Kidney & Cat & 49.3 & 200 & 18 \\
Liver & Cat & 54.1 & 200 & 18 \\
Spleen & Cat & 378.6 & 500 & 18 \\
\hline
\end{tabular}

${ }^{a}$ The results shown represent the mean of eight rat brains and duplicate cat tissues. Although the present results generally suggest lower $t$-MH levels, the values compare favorably with those of White (18).

the formation of the TFA derivatives at room temperature without pyridine, although Navert did not report the extent of derivatization or the identity of the derivatives. As mentioned, under these conditions only the monoderivatives are formed. It should be pointed out that the bis-derivatives are clearly preferable for the gc analysis of the compounds, whether the detector is a mass spectrometer or an electron capture device. The higher masses are more desirable for the former and the addition of the haloacyl group to the aromatic nucleus would enhance detection by the latter. Both Navert (12) and Mahy and Gelpi (13) have reported that the $N$-trimethylsilyl derivatives of $t$ - and $p$-MH can be successfully formed and detected by gc. The latter authors also presented mass spectral evidence for the existence of the bis- $(N-$ trimethylsilyl)- $t-\mathrm{MH}$, although the stability or the extent of derivatization was not mentioned. To our knowledge, the current report is the first successful gc application for the analysis of $t$-MH from tissue sources.

The assay, as described under Methods, represents several improvements over an earlier method, the subject of a preliminary communication (14). Thus, chloroform has been replaced by butanol-chloroform in the first organic extraction. The latter, although somewhat less selective, gives higher recoveries. The evaporation of the chloroform at room temperature under nitrogen resulted in the loss of $20-30 \%$ of $t$-MH as the free base. This step has been replaced by the back-extraction with a small volume of acid. The subsequent evaporation to dryness produces a residue which can be stored for several days at $4^{\circ} \mathrm{C}$ without sample decomposition. The use of HFBA as the derivatizing reagent is best, not only because of the selectivity of the higher masses, but because of the increased lipophilicity of the derivatives, permitting the benzene extraction. Because of its lesser toxicity, toluene probably can and should be used instead of benzene. The optimum $\mathrm{pH}$ has been determined to be between 6.5 and 8 for this extraction, since significant imidazole ionization probably occurs below this range and losses in recovery were realized using solutions whose $\mathrm{pH}$ were 9 or higher. Thus, benzene extractions of derivatives from $\mathrm{pH} 13$ solutions gave no products, presumably due to breakdown. When used as described, the Tris buffer yields solutions of $\mathrm{pH} 6.5$ to 7.5. The difficulties in attaining $\mathrm{pH} 8$ are enhanced by the pyridine, $\mathrm{p} K_{a} 5.2$, and by the limited volume of the vials used.

Our findings of no $p-\mathrm{MH}$ in rat brain are similar to the earlier report of Nakajima et al. (15) who found none in bovine brain. 
It is also of considerable interest that no $p$-MH was found in other tissues examined, since its carboxylated analog (1- or prosmethylhistidine) is a known constituent of anserine (16) and homoanserine (17). Caution must be made in using the present internal standard in tissue without first examining it for endogenous $p$ - $\mathrm{MH}$, particularly in muscle where the methylated amino acid may exist in measurable quantities.

The present results confirm those of Fram and Green (8) who suggested that the rat brain contains $t$-MH. The $t$ - MH content (mean \pm SEM) has now been found to be $42 \pm 3.2 \mathrm{ng} / \mathrm{g}$ (Table 2). Furthermore, the value is similar to that found for the guinea pig brain. The lack of sensitivity of the previously used method is probably the explanation for one investigator's inability to identify rat brain $t$-MH (18). We have recently described the regional rat brain $t$-MH as well (19). The $t$-MH content found in the cat tissues suggests that previous methods may have slightly overestimated the values. With the exception of the lung, however, the values compare favorably. This is all the more impressive when it is realized that each value was obtained by the assay of the combined organs of six cats. The large variation in the $t-\mathrm{MH}$ content of these organs may be due to variable amounts of diamine oxidase or to different turnover rates of histamine in these tissues.

\section{ACKNOWLEDGMENTS}

The authors would like to thank Dr. J, C. Emmett and Dr. C. R. Ganellin for the synthesis and generous donation of the precious samples of pros-methylhistamine.

\section{REFERENCES}

1. Maslinski, C. (1975) Agents Actions 5, 183-225.

2. Brown, D. D., Tomchick, R., and Axelrod, J. (1959). J. Biol. Chem. 234, 2948-2950.

3. Black, J. W., and Ganellin, C. R. (1974). Experientia 30, 111-113.

4. Schwartz, J. C. (1977) Ann. Rev, Pharmacol. Toxicol. 17, 325-340.

5. Schwartz, J. C., Baudry, M., Chast, F., Pollard, H., Bischoff, S., and Krishnamoorthy, M. S. (1974) in Metabolic Regulation and Function Activity in the Central Nervous System (Genazzi, E., and Herkin, H., eds.) SpringerVerlag, Amsterdam.

6. Hough, L. B., and Domino, E. F. (1979) J. Pharmacol. Exp. Ther., 200, in press.

7. Phillis, J. W., Tebecis, A. K., and York, D. H. (1968) Brit. J. Pharmacol. 33, 426-440.

8. Fram, D. H., and Green, J. P. (1963) Pharma cologist 5, 253.

9. Fram, D. H., and Green, J. P. (1965) J. Biol. Chem. 240, 2036-2042.

10. Fram, D. H., and Green, J. P. (1968) J. Neurochem. 15, 597-602.

11. White, T. (1966) Brit. J. Pharmacol. 26, 494-501.

12. Navert, H., (1975) J. Chromatogr. 106, 218-224.

13. Mahy, N., and Gelpi, E. (1977) J. Chromatogr. 130, 237-242.

14. Hough, L. B., and Domino, E. F. (1977) Fed. Proc. 36, 969.

15. Nakajima, T., Wolfgren, F., and Clark, W. G. (1967) I. Neurochem. 14, 1113-1118.

16. Cooper, J. R., Bloom, F. E., and Roth, R. H. (1974) The Biochemical Basis of Neuropharmacology, p. 212, Oxford Univ, Press, London/New York.

17. Mahler, H. R., and Cordes, E. H. (1971) Biological Chemistry, p. 66, Harper \& Row, New York.

18. White, T. (1973) in International Encyclopedia of Pharmacology and Therapeutics, Sect. 74 (Schacter, M., ed.), Vol. 1, pp. 101-107, Pergamon, London/New York.

19. Hough, L. B., and Domino, E. F. (1979) $d$, Neurochem., in press. 